\title{
COMPOSIÇÃO FENÓLICA, ATIVIDADE ANTIBACTERIANA E ANTIOXIDANTE DA PRÓPOLIS VERMELHA BRASILEIRA
}

Ingridy Simone Ribeiro Cabral, Tatiane Luiza Cadorin Oldoni, Adna Prado, Rosângela Maria Neves Bezerra e Severino Matias de Alencar*

Departamento de Agroindústria, Alimentos e Nutrição, Escola Superior de Agricultura “Luiz de Queiroz”, Universidade de São Paulo, CP 9, 13148-900 Piracicaba - SP, Brasil

Masaharu Ikegaki

Departamento de Farmácia, Universidade Federal de Alfenas, Rua Gabriel Monteiro da Silva, 700, 37130-000 Alfenas - MG, Brasil Pedro Luiz Rosalen

Departamento de Ciências Fisiológicas, Faculdade de Odontologia de Piracicaba, Universidade Estadual de Campinas, CP 52, 13414-903 Piracicaba - SP, Brasil

Recebido em 12/8/08; aceito em 4/2/09; publicado na web em 3/7/09

\begin{abstract}
PHENOLIC COMPOSITION, ANTIBACTERIAL AND ANTIOXIDANT ACTIVITIES OF BRAZILIAN RED PROPOLIS. Propolis is a resinous hive product collected by honeybees from various plant sources. It has a complex chemical composition, constituted by various phenolic compounds. Extracts of increasing polarity (n-hexane, chloroform, and ethanol) were obtained from a sample of red propolis from the state of Alagoas. Assays were carried out for determination of contents of phenolics, along with antibacterial and antioxidant activities. The EEP, fractions and sub-fractions showed strong biological activities and were related with phenolic the content compounds contents. The sub-fractions were more bioactive than the EEP and fractions, demonstrating that the antioxidant and antibacterial activities are not a result of synergistic effect between the various chemical compounds in propolis.
\end{abstract}

Keywords: red propolis; antioxidant; antibacterial activity.

\section{INTRODUÇÃO}

A própolis é uma substância resinosa coletada pelas abelhas a partir de exsudatos de brotos e botões florais de diversas plantas. Possui coloração e consistência variada e é utilizada pelas abelhas para reparar os favos de mel, para fechar pequenas frestas, embalsamar insetos mortos, bem como proteger a colméia contra a invasão de micro-organismos. ${ }^{1}$

A composição química da própolis é dependente da biodiversidade da região visitada pelas abelhas. ${ }^{2}$ Portanto, as substâncias presentes encontram-se diretamente relacionadas com a composição química da resina da planta de origem. ${ }^{3}$

Os compostos fenólicos, dentre eles os flavonoides, têm sido considerados como um dos principais constituintes biologicamente ativos da própolis, ${ }^{4-7}$ juntamente com os derivados do ácido cinâmico e seus ésteres ${ }^{8}$ e os diterpenos. ${ }^{8,9}$

A proporção dos compostos fenólicos é variável e também depende do local e da época da coleta. ${ }^{1,3,10}$ Devido à composição química complexa e variável da própolis, várias são as atividades biológicas relatadas na literatura, tais como antimicrobiana, ${ }^{5,11,12,13}$ anticariogênica, ${ }^{3,14,15}$ citotóxica, ${ }^{5,8,12,16,17}$ anti-inflamatória, ${ }^{18}$ imunomodulatória, ${ }^{12,19,20}$ antioxidante $\mathrm{e}^{5,11,21}$ e antitumoral..$^{22}$

A amplitude das atividades biológicas da própolis é maior em áreas tropicais do planeta, refletindo a diversidade vegetal destas regiões. ${ }^{23}$ Devido a grande diversidade da flora brasileira, as própolis do Brasil puderam ser agrupadas em 12 grupos distintos, de acordo com a composição química e atividades biológicas. ${ }^{2}$ Atualmente um novo tipo de própolis proveniente da região de mangue do Estado de Alagoas teve sua origem botânica identificada como Dalbergia ecastophyllum, uma espécie de leguminosa. ${ }^{24}$ Esta própolis, denominada de "própolis vermelha" por causa da sua coloração vermelha

*e-mail: alencar@esalq.usp.br intensa, foi classificada como o $13^{\circ}$ tipo de própolis brasileira ${ }^{24} \mathrm{e}$ tem demonstrado várias atividades biológicas em ensaios in vitro. ${ }^{5}$

Considerando que o fracionamento é o passo inicial na identificação de compostos bioativos de produtos naturais, ${ }^{15}$ o presente trabalho teve como objetivos fracionar, avaliar a composição fenólica, as atividades antibacteriana e antioxidante da própolis vermelha brasileira.

\section{PARTE EXPERIMENTAL}

\section{Amostra de própolis}

A própolis vermelha foi obtida de coletores colocados nas caixas de abelhas Apis mellifera, em março de 2005, em um apiário localizado na cidade de Marechal Deodoro, Estado de Alagoas, no Nordeste do Brasil. A amostra de própolis bruta foi submetida à limpeza, retirando-se qualquer tipo de material estranho. Em seguida, foi triturada mediante a adição de nitrogênio líquido, homogeneizada, pesada e armazenada a $-18^{\circ} \mathrm{C}$.

\section{Extração e fracionamento da própolis vermelha}

A própolis bruta triturada $(100 \mathrm{~g})$ foi submetida à extração utilizando-se $400 \mathrm{~mL}$ de etanol $80 \%$ (v/v). A extração foi realizada a $70{ }^{\circ} \mathrm{C}$, em banho de água termostatizado, durante $30 \mathrm{~min}$, sob agitação constante. A filtração foi realizada em papel de filtro e o extrato etanólico de própolis (EEP) resultante foi fracionado pela técnica de extração líquido-líquido, em funil de separação, com hexano e clorofórmio, separadamente. Após a evaporação foram obtidas 11,36 g da fração hexânica (fr-Hex) e 30,08 g da fração clorofórmica (fr-Clo). Somente a fr-Clo foi utilizada para ser refracionada em cromatografia em coluna empacotada com $40 \mathrm{~g}$ de sílica-gel (G60 Merck 70-230 mesh; tamanho de partícula 0,063-0,02 mm). Foi aplicado 1,0 g da fr-Clo e a coluna eluída com um sistema de solvente composto por 
clorofórmio e acetato de etila (7:3). Após a eluição, as cinco subfrações foram filtradas para a retirada da sílica e evaporadas à pressão reduzida em rotaevaporador a $50{ }^{\circ} \mathrm{C}$, para fornecer 0,$15 ; 0,10 ; 0,34$; 0,09 e $0,13 \mathrm{~g}$ das sub-frações $1,2,3,4$ e 5 , respectivamente, as quais foram utilizadas nos testes de atividade antioxidante, antimicrobiana e determinação de compostos fenólicos.

\section{Cromatografia líquida de alta eficiência em fase reversa (CLAE-FR)}

As análises por CLAE em fase reversa das sub-frações foram feitas de acordo com o método descrito por Alencar et al. ${ }^{5}$ Quinze microlitros do EEP e das frações hexânica e clorofórmica, na concentração de $1 \%$ em etanol P.A. (m/v), foram injetados em um cromatógrafo líquido acoplado a um detector de arranjo de fotodiodos a $260 \mathrm{~nm}$ e uma coluna de fase reversa C18 (250 x 4,6 mm) com tamanho de partícula de $5 \mu \mathrm{m}$. A fase móvel utilizada foi água/ácido acético (19:1, v/v) (solvente A) e metanol (solvente B), com vazão constante de $1 \mathrm{~mL} / \mathrm{min}$. O gradiente iniciou com $40 \%$ do solvente B até $60 \%$ de B em $45 \mathrm{~min}, 90 \%$ de B em 75 min, retornando a $40 \%$ de B após 85 min. A identificação dos compostos químicos foi realizada pela comparação direta com padrão autêntico, baseada no tempo de retenção, cocromatografia e absorção espectrofotométrica.

Os seguintes padrões autênticos de flavonoides e ácidos fenólicos foram utilizados (Extrasynthese Co.): quercetina, canferol, apigenina, pinocembrina, crisina, acacetina, galangina, canferide, isosacuranetina, sacuranetina, raminetina, formononetina, isorraminetina, rutina, ácido gálico, ácido $\rho$-cumárico, ácido cinâmico e ácido ferúlico.

\section{Teor de compostos fenólicos totais}

Para a determinação do teor de fenólicos totais, ${ }^{25}$ uma solução de EEP, frações ou sub-frações $(0,5 \mathrm{~mL})$ foi misturada com $2,5 \mathrm{~mL}$ do reagente Folin-Ciocalteau (diluído 1:10) e com 2,0 mL de $\mathrm{Na}_{2} \mathrm{CO}_{3}$ $4 \%(\mathrm{~m} / \mathrm{v})$. Após $2 \mathrm{~h}$ de incubação no escuro à temperatura ambiente, a absorbância foi medida em espectrofotômetro (UV Mini 1240) a $740 \mathrm{~nm}$. Os resultados do teor de compostos fenólicos totais foram expressos como equivalentes de ácido gálico (mg AG/g), calculados por meio de uma curva construída com concentrações que variaram de 5 a $100 \mu \mathrm{g} / \mathrm{mL}$. O EEP, frações e sub-frações foram avaliados na concentração final de $200 \mu \mathrm{g} / \mathrm{mL}$.

\section{Atividade sequestradora do radical livre DPPH}

A medida da atividade sequestradora do radical DPPH do EEP, frações e sub-frações foi realizada de acordo com a metodologia descrita por Brand-Willians, Cuvelier e Berset. ${ }^{26}$ A mistura de reação foi constituída da adição de $0,5 \mathrm{~mL}$ de EPP, frações ou sub-frações, $3 \mathrm{~mL}$ de etanol e $0,3 \mathrm{~mL}$ da solução $0,5 \mathrm{mM}$ do radical DPPH em etanol. A leitura da absorbância foi feita em espectrofotômetro a $517 \mathrm{~nm}$ (UV Mini 1240), após 45 min. As amostras e as substâncias de referência, butil-hidroxitolueno (BHT), $\alpha$-tocoferol e butil- hidroxianisol (BHA) foram avaliadas na concentração final de $90 \mu \mathrm{g} / \mathrm{mL}$. A atividade antiradical foi determinada na forma de atividade antioxidante (AA), calculada por meio da taxa de declínio da absorbância da solução de DPPH - amostras e padrões, após 45 min de reação (fase estável) em relação à solução referência (DPPH em etanol), de acordo com a fórmula:

$\%$ Atividade antioxidante $\left.=100-\left(\left(\mathrm{A}_{\text {amostra }}-\mathrm{A}_{\text {branco }}\right) * 100\right) / \mathrm{A}_{\text {controle }}\right)$

onde: $\mathrm{A}_{\text {amostra }}=$ absorbância da solução DPPH (amostras); $\mathrm{A}_{\text {branco }}=$ absorbância da solução das amostras sem adição de DPPH; $\mathrm{A}_{\text {controle }}=$ absorbância da solução referência de DPPH (etanol)

\section{Atividade antioxidante pela oxidação acoplada do sistema} $\beta$-caroteno/ácido linoleico

A medida da atividade antioxidante foi determinada pela oxidação acoplada do $\beta$-caroteno e do ácido linoleico, de acordo com Ahn et al. ${ }^{27}$ Foram pesados $10 \mathrm{mg}$ de $\beta$-caroteno, os quais foram dissolvidos em $100 \mathrm{~mL}$ de clorofórmio. Após isto, foi retirada uma alíquota de $3 \mathrm{~mL}$ da solução clorofórmio - $\beta$-caroteno e adicionada a $40 \mathrm{mg}$ de ácido linoleico e $400 \mathrm{mg}$ de Tween 40. Em seguida, o clorofórmio foi removido com a utilização de uma corrente de gás nitrogênio, e o resíduo obtido redissolvido em $100 \mathrm{~mL}$ de água aerada durante 30 min. Alíquotas de $3 \mathrm{~mL}$ da emulsão $\beta$-caroteno/ácido linoleico foram misturadas com $50 \mu \mathrm{L}$ do EEP, frações e sub-frações. A oxidação da emulsão foi monitorada espectrometricamente (UV Mini 1240) a $470 \mathrm{~nm}$, no tempo inicial e após 120 min de incubação a $50{ }^{\circ} \mathrm{C}$. A atividade antioxidante foi expressa pela porcentagem de inibição relativa em relação ao controle depois de 120 min de incubação, de acordo com a seguinte Equação:

$\mathrm{AA}=\left(\mathrm{R}_{\text {Controle }}-\mathrm{R}_{\text {Amostra }}\right) / \mathrm{R}_{\text {Controle }} \mathrm{X} 100$

onde: $\mathrm{R}_{\text {controle }}$ e $\mathrm{R}_{\text {amostra }}$ representam as taxas de branqueamento do $\beta$-caroteno sem e com a adição de antioxidante, respectivamente. As taxas de degradação $\left(R_{D}\right)$ foram calculadas de acordo com a cinética de primeira ordem:

$\left.\mathrm{R}_{\mathrm{D}}=\ln (a / b) \times 1 / \mathrm{t}\right)$

onde: ln é o logaritmo natural, $a$ a absorbância inicial no tempo 0 e $b$ a absorbância depois de 120 min e $t$ o tempo total da reação. O EEP, frações e sub-frações foram avaliados na concentração final de $200 \mu \mathrm{g} / \mathrm{mL}$ e as substâncias referência na concentração de $90 \mu \mathrm{g} / \mathrm{mL}$.

\section{Atividade antibacteriana}

A atividade antibacteriana foi realizada por meio da determinação da Concentração Inibitória Mínima (CIM) e Concentração Bactericida Mínima (CBM) de acordo com a metodologia descrita por Cabral. ${ }^{28} \mathrm{O}$ micro-organismo Staphylococcus aureus ATCC 25923 foi inicialmente reativado a partir das culturas estoque em meio BHI líquido (Brain Heart Infusion) por $18-24$ h a $37{ }^{\circ} \mathrm{C}, 10 \%$ de $\mathrm{CO}_{2}$ e, posteriormente, cultivado em placas BHI ágar. Após o crescimento bacteriano, as colônias individuais foram removidas com auxílio de uma alça de platina e suspendidas em uma solução de $\mathrm{NaCl}$ 0,89\% estéril. Após a homogeneização, as suspensões bacterianas foram ajustadas para o valor de absorbância de 0,135 a $660 \mathrm{~nm}$ em espectrofotômetro, o que equivale a $1-2 \times 10^{8} \mathrm{UFC} / \mathrm{mL}$. Um volume de $30 \mu \mathrm{L}$ das suspensões bacterianas foram inoculados em $30 \mathrm{~mL}$ do meio BHI, de modo a se obter uma concentração bacteriana em torno de 1-2 x $10^{5} \mathrm{UFC} / \mathrm{mL}$, sendo a mistura homogeneizada por meio de um agitador magnético.

A técnica foi desenvolvida em microplacas de 96 poços, nos quais foram adicionados $190 \mu \mathrm{L}$ de caldo BHI previamente inoculado. Em seguida, foram adicionados $10 \mu \mathrm{L}$ do EEP, frações e sub-frações em concentrações que variaram de 500 a $3,9 \mu \mathrm{g} / \mathrm{mL}$ (diluição seriada de razão 2). Como controle positivo foi utilizada a clorexidina $0,12 \%$ $(\mathrm{m} / \mathrm{v})$ e como controle negativo foi utilizado o etanol $80 \%(\mathrm{v} / \mathrm{v})$, solvente utilizado para solubilizar o EEP, frações e sub-frações. As microplacas foram incubadas a $37{ }^{\circ} \mathrm{C}$ por $24 \mathrm{~h}$. Após a incubação, foram adicionados $30 \mu \mathrm{L}$ do corante Resazurina $(0,01 \% ; \mathrm{m} / \mathrm{v})$ para se verificar em quais poços houve crescimento bacteriano. Nos poços em que não houve mudança na cor do corante, ou seja, permaneceu roxo, foi considerada a ausência de bactérias viáveis. Qualquer evidência na mudança da coloração se considerou crescimento bacteriano. 

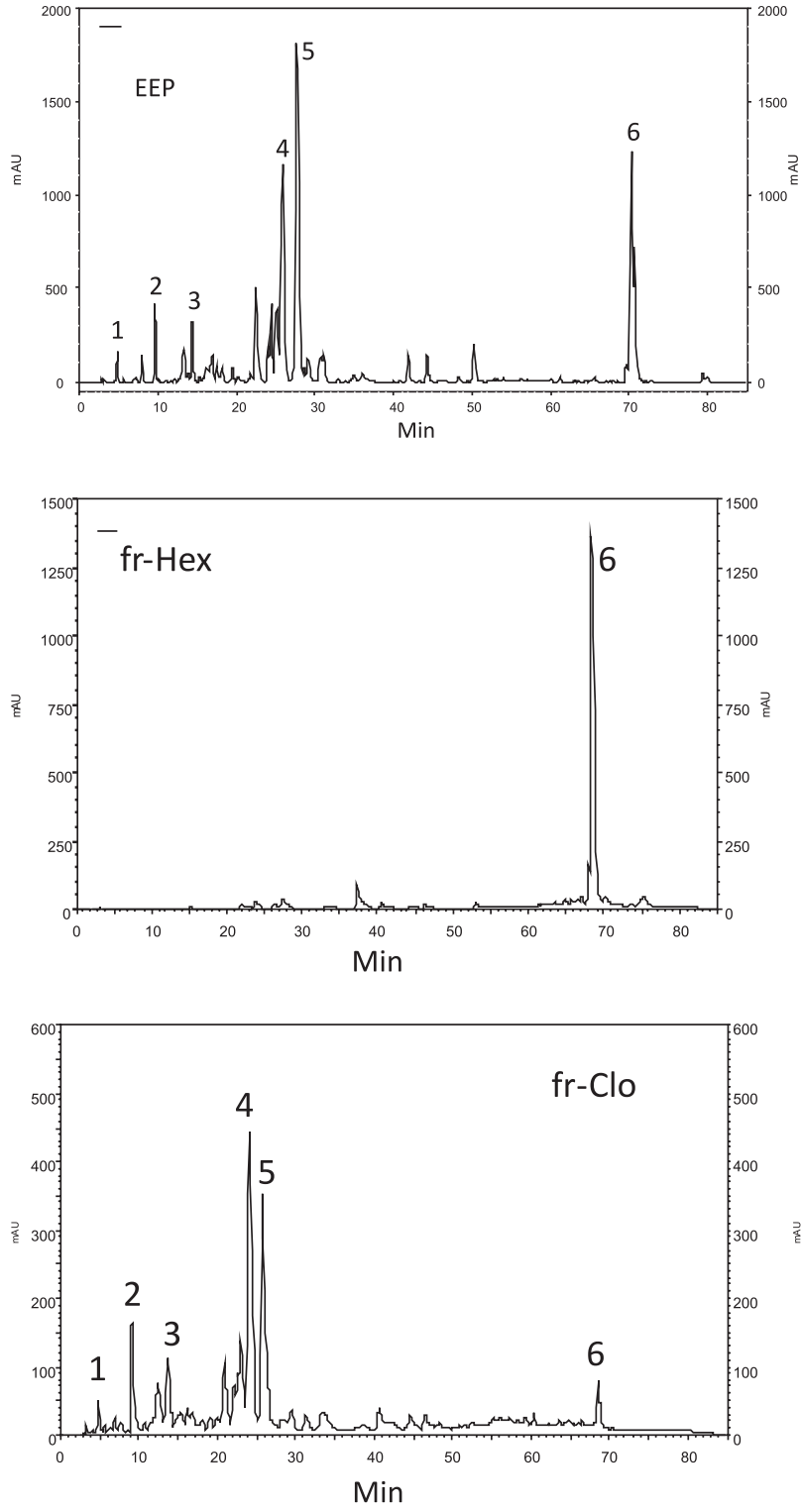

Figura 1. Cromatogramas obtidos por CLAE-FR do extrato etanólico bruto da própolis vermelha (EEP), da fração hexânica (fr-Hex.) e fração clorofórmica (fr-Clo.). 1. Ácido ferúlico; 2. Daidzeina; 3. Quercetina; 4. UV $\lambda$ 230, 242, $372 \mathrm{~nm}^{*}$; 5. Formononetina; 6. UV $\lambda$ 227, 247, $359 \mathrm{~nm} *$. * Constituintes não identificados, representados apenas pelos espectros de absorção máxima no UV

Para a determinação da CBM, alíquotas de $10 \mu \mathrm{L}$ do meio de cultura dos poços considerados inibitórios foram semeadas em placas de Petri contendo BHI ágar e incubados a $37^{\circ} \mathrm{C}$ por $24 \mathrm{~h}$. A CBM foi considerada como a menor concentração na qual não houve crescimento de colônias na superfície do meio de cultura.

\section{RESULTADOS E DISCUSSÃO}

A composição química da própolis é altamente dependente da localização geográfica. A própolis vermelha brasileira apresenta uma coloração vermelha intensa, além de uma composição química distinta dos outros 12 tipos de própolis brasileira. ${ }^{5}$ Quando o EEP foi submetido ao fracionamento líquido-líquido com hexano e clorofórmio, foram obtidas duas frações, fração hexânica (fr-Hex) e fração clorofórmica (fr-Clo) com rendimentos de 11,36 e 30,08\%, respectivamente. O EEP e as frações foram analisados por CLAE-FR para avaliação do perfil químico (Figura 1).

$\mathrm{O}$ EEP apresentou uma composição química semelhante à fr-Clo e diferente da fr-Hex, a qual apresentou apenas um pico majoritário e de natureza apolar, o qual não foi identificado. A identificação dos compostos químicos foi realizada pela comparação direta com padrão autêntico e baseada no tempo de retenção, cocromatografia e absorção espectrofotométrica. Apenas o flavonoide quercetina, as isoflavonas formononetina e daidzeina e os ácidos fenólico e ferúlico foram identificados no EEP e na fr-Clo. A maioria dos compostos usados como padrão e comumente encontrados em outros tipos de própolis brasileiras não foi identificada. Esses resultados corroboraram com a literatura recente, demonstrando que a própolis vermelha é realmente um novo tipo de própolis brasileira., ${ }^{54}$

Pelo fato da fr-Clo possuir uma composição química complexa em relação à fr-Hex, esta fração foi refracionada em coluna seca de sílica-gel, a qual gerou 5 sub-frações (Tabela 1).

Tabela 1. Teor de compostos fenólicos totais do extrato etanólico da própolis vermelha, frações e sub-frações

\begin{tabular}{lc}
\hline Amostra & Fenólicos Totais (mg AG/100 g de própolis)* \\
\hline EEP & $257,98^{\mathrm{b}}$ \\
fr- Hex. & $154,83^{\mathrm{e}}$ \\
fr- Clo. & $249,75^{\mathrm{b}}$ \\
Sub-fração 01 & $143,85^{\mathrm{e}}$ \\
Sub-fração 02 & $176,23^{\mathrm{d}}$ \\
Sub-fração 03 & $286,78^{\mathrm{a}}$ \\
Sub-fração 04 & $295,29^{\mathrm{a}}$ \\
Sub-fração 05 & $235,89^{\mathrm{c}}$ \\
\hline
\end{tabular}

*Médias $(\mathrm{n}=3)$ seguidas de letras diferentes são significativas em nível de $5 \% \quad$ (Teste de Tukey $\mathrm{p}<0,05$ ).

O teor de compostos fenólicos do EEP, frações e sub-frações está mostrado na Tabela 1. Foi possível observar que o EEP apresentou um teor de 257,98 mg AG/g, sendo este o maior valor encontrado em amostras de própolis brasileiras. ${ }^{5,29} \mathrm{~A}$ fr-Hex apresentou um teor de compostos fenólicos estatisticamente menor (154,83 mg AG/g) quando comparado ao teor da fr-Clo (249,75 mg AG/g) e ao EEP $(257,98$ $\mathrm{mg} \mathrm{AG/g).} \mathrm{Este} \mathrm{resultado} \mathrm{demonstra} \mathrm{que} \mathrm{existem} \mathrm{compostos} \mathrm{fenólicos}$ de diferentes polaridades no extrato bruto que foram separados pela técnica de fracionamento líquido-líquido. Já nas sub-frações obtidas pelo fracionamento em coluna seca de sílica-gel os teores variaram de 143,85 e $295,29 \mathrm{mg} \mathrm{AG/g}$.

As sub-frações mais polares (03 e 04) apresentaram as maiores concentrações, sendo estatisticamente diferentes de todas as outras amostras. Devido aos altos teores de compostos fenólicos encontrados nesta própolis, o EEP, frações e sub-frações foram avaliados quanto às atividades antibacteriana e antioxidante, já que esta classe de substâncias tem sido relacionada com várias atividades biológicas. ${ }^{30}$

A atividade antioxidante foi avaliada por dois métodos distintos, o sequestro de radical $\mathrm{DPPH}^{\bullet}$ e a inibição da oxidação do sistema $\beta$-caroteno/ácido linoleico. O radical DPPH' é muito usado para se avaliar a capacidade sequestradora de produtos apícolas, ${ }^{31}$ chás, ${ }^{32}$ extratos de frutas ${ }^{33}$ e ervas. ${ }^{34} \mathrm{O}$ radical livre $\mathrm{DPPH}^{\bullet}$ é um cromóforo extremamente estável que apresenta uma banda de absorção no comprimento de onda de $515 \mathrm{~nm}$ em meio alcoólico e possui uma coloração violeta intensa. ${ }^{35}$ Conforme o DPPH vai sendo reduzido por um antioxidante, seu elétron torna-se emparelhado e a absortividade 
desaparece. ${ }^{26}$ No sistema $\beta$-caroteno/ácido linoleico a atividade de uma amostra ou composto em proteger um substrato lipídico, representada pela oxidação do $\beta$-caroteno, é determinada por meio da atividade de inibição de radicais livres gerados durante a peroxidação do ácido linoleico. ${ }^{36}$

Conforme demonstrado na Figura 2, a fr-Hex foi a que apresentou maior atividade de sequestro do radical livre $\mathrm{DPPH}^{*}(74,4 \%)$, seguida pelo EEP $(50,5 \%)$ e fr-Clo $(49,8 \%)$. Todas as sub-frações apresentaram atividade superior a $43 \%$, tendo as sub-frações 5 e 3 apresentado as maiores atividades, 80,94 e 77,53\%, respectivamente. Diferenças entre os resultados da atividade antioxidante podem acontecer por diversas causas, como concentração da amostra e método de determinação (sequestro de radicais ou oxidação lipídica, tempo de reação e solvente utilizado). ${ }^{37} \mathrm{~A}$ determinação da atividade antioxidante também poder ser influenciada pela afinidade dos antioxidantes e o método do DPPH tem se mostrado vantajoso, pois o resultado não é afetado pela polaridade do substrato, ${ }^{38}$ ou seja, os compostos da fr-Hex são mais efetivos que os da fr-Clo. Corroborando com este trabalho, Trusheva et al. ${ }^{6}$ isolaram compostos da própolis vermelha e verificaram que as benzofenas isopreniladas, substâncias de menor polaridade em relação aos isoflavonoides, apresentaram maior potencial antioxidante. De fato, Oldoni ${ }^{39}$ também encontrou benzofenonas isopreniladas na fração hexânica da própolis vermelha pela técnica de espectrometria, sendo inclusive uma mistura de isômeros.

Com relação à atividade antioxidante pelo método da inibição da oxidação do sistema $\beta$-caroteno/ácido linoleico, mostrado na Figura 3 , a fr-Clo foi a fração que apresentou a melhor atividade antioxidante $(64,84 \%)$ sendo semelhante ao EEP $(61,26 \%)$. Apesar da fr-Hex ter apresentado alta porcentagem de sequestro para o radical livre DPPH ${ }^{*}$ (Figura 2), não foi eficiente em inibir a peroxidação lipídica in vitro (Figura 3), em que a atividade antioxidante foi inferior a 40\%. As subfrações 2, 3, 4 e 5 demonstraram atividade antioxidante superior a $60 \%$, não apresentando diferença estatisticamente significativa (Figura 3).

A atividade antioxidante determinada pelo teste de sequestro do radical DPPH (Figura 2) parece não estar relacionada com a atividade determinada pelo método de descoloração do $\beta$-caroteno, apresentado na Figura 3. Estas diferenças podem estar relacionadas com o fato de que em sistemas lipofílicos as taxas de reações de sequestro podem ser influenciadas pelo coeficiente de partição dos compostos entre as fases aquosa e lipídica e, desta forma, reduzir a disponibilidade dos compostos polares para reação com o radical não-polar LOO ${ }^{40}$

A correlação entre compostos fenólicos e atividade sequestradora do radical livre DPPH $\left(r^{2}=0,23\right)$ apresentou-se positiva, de fraca a

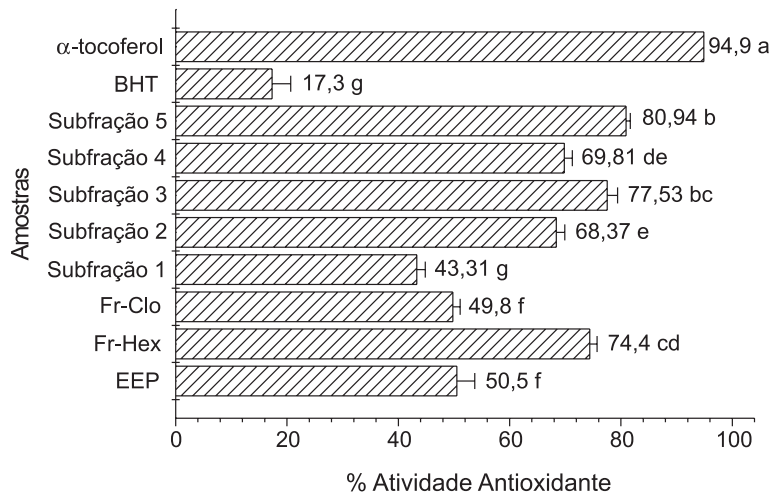

Figura 2. Atividade sequestradora do radical livre DPPH pelo $\alpha$-tocoferol, $B H T$, EEP, frações e sub-frações da própolis vermelha. Médias e desvios padrões estão indicados $(n=3)$. Médias seguidas de letras diferentes são significativas em nível de 5\% (Teste de Tukey $p<0,05$ )

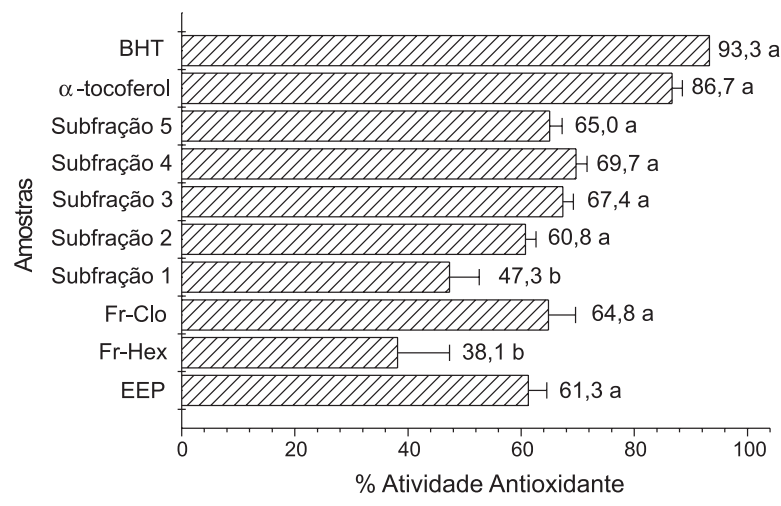

Figura 3. Atividade antioxidante do BHA, $\alpha$-tocoferol, BHT e sub-frações no sistema $\beta$-caroteno-ácido linoleico. Médias e desvios padrões estão indicados $(n=3)$. Médias seguidas de letras diferentes são significativas em nível de $5 \%$ (Teste de Tukey $p<0,05$ )

moderada. Uma correlação mais alta e positiva $\left(r^{2}=0,86\right)$ foi observada entre os compostos fenólicos e a atividade antioxidante pela oxidação do sistema $\beta$-caroteno/ácido linoleico (Tabela 2).

Tabela 2. Coeficiente de correlação (r) entre o teor de fenólicos totais e a atividade antioxidante

\begin{tabular}{lc}
\hline Correlação & $\mathrm{r}^{2}$ \\
\hline Atividade antioxidante & \\
DPPH x compostos fenólicos & 0,23 \\
Oxidação do ác. linoleico x compostos fenólicos & 0,86 \\
\hline
\end{tabular}

A correlação positiva indica que os compostos fenólicos possuem importante função na atividade antioxidante apresentada pelo EEP, frações e sub-frações, mas, certamente outros fatores também estão envolvidos.

A própolis vermelha demonstrou alta atividade antibacteriana frente à bactéria Staphylococcus aureus ATCC 25923 (Tabela 3).

Com uma CIM variando entre 62,5 e $125 \mu \mathrm{g} / \mathrm{mL}$ e uma CBM entre 250 e $500 \mu \mathrm{g} / \mathrm{mL}$, o EEP demonstrou potencial antibacteriano em concentrações menores em relação a outros estudos anteriores de própolis brasileiras. ${ }^{19,29} \mathrm{~A}$ fr-Clo teve a atividade potencializada (CIM entre 31,7 e $62,5 \mu \mathrm{g} / \mathrm{mL}$ e CBM entre 125 e $250 \mu \mathrm{g} / \mathrm{mL}$ ), sendo estas concentrações reduzidas em $50 \%$ quando comparadas à atividade do EEP. Todas as sub-frações apresentaram alta atividade antibacteriana, sendo que as sub-frações 3 e 4 apresentaram a CIM entre 15,8 e 31,7 $\mu \mathrm{g} / \mathrm{mL}$. A melhor atividade bactericida foi obtida pela sub-fração 4 , sendo a CBM entre 31,7- 62,5 $\mu \mathrm{g} / \mathrm{mL}$, valor este oito vezes menor que a concentração de EEP necessária para apresentar efeito bactericida frente a $S$. aureus. Esta alta atividade antibacteriana das sub-frações 3 e 4 pode estar relacionada ao alto teor de compostos fenólicos destas duas sub-frações, conforme mostrado na Tabela 1. Os resultados obtidos para a CIM e CBM revelaram que o potencial antibacteriano foi aumentando à medida que o extrato foi fracionado (Tabela 3). A atividade antimicrobiana superior das sub-frações pode ser explicada em função da maior quantidade relativa dos componentes biologicamente ativos em relação aos componentes totais (EEP, fr-Hex, fr-Clo).

Resultados semelhantes também foram encontrados por outros autores. Duarte et al. ${ }^{14}$ obtiveram frações biologicamente mais potentes que o extrato bruto da própolis tipo 6, proveniente da Bahia, ao fracionar o EEP com hexano e clorofórmio. O mesmo ocorreu com as própolis tipo 3 e tipo 12, provenientes respectivamente das regiões sul e sudeste do Brasil, ao serem fracionadas com hexano e 
Tabela 3. Concentração Inibitória Mínima (CIM) e Concentração Bactericida Mínima (CBM) do EEP, frações e sub-frações frente a Staphylococcus aureus ATCC 25923

\begin{tabular}{lcc}
\hline Amostra & CIM $(\mu \mathrm{g} / \mathrm{mL})$ & CBM $(\mu \mathrm{g} / \mathrm{mL})$ \\
\hline EEP & $62,5-125$ & $250-500$ \\
fr-Hex & $125-250$ & $250-500$ \\
fr-Clo & $31,7-62,5$ & $125-250$ \\
Sub-fração 1 & $31,7-62,5$ & $62,5-125$ \\
Sub-fração 2 & $31,7-62,5$ & $62,5-125$ \\
Sub-fração 3 & $15,8-31,7$ & $62,5-125$ \\
Sub-fração 4 & $15,8-31,7$ & $31,7-62,5$ \\
Sub-fração 5 & $31,7-62,5$ & nd* \\
\hline
\end{tabular}

*nd: não determinada.

clorofórmio, pois apresentaram atividade inibitória e bactericida em concentrações bem menores que as requeridas pelo EEP. ${ }^{15}$

\section{CONCLUSÃO}

Pode-se concluir que a própolis vermelha brasileira possui alta atividade antioxidante e antibacteriana e que o fracionamento produziu sub-frações biologicamente mais ativas que as frações e o EEP. A fr-Hex apresentou a maior atividade sequestradora de radicais livres $(74,4 \%)$ em relação ao EEP e a fr-Clo, o que pode ser explicado pelo alto potencial das substâncias antioxidantes presentes, visto que o método do DPPH não é influenciado pela polaridade do substrato. Já o método do $\beta$-caroteno emprega um emulsificante lipídico, o qual introduz um grande número de variáveis que influenciam a oxidação em comparação aos lipídeos puros, afetando assim o comportamento dos outros antioxidantes. Por outro lado, as substâncias antibacterianas concentraram-se na fr-Clo, demonstrando assim que os compostos bioativos para estas duas propriedades biológicas são de natureza química distinta. Portanto, as atividades antioxidante e antibacteriana da própolis vermelha não são função de um efeito sinérgico entre os vários compostos presentes no extrato bruto.

\section{AGRADECIMENTOS}

À FAPESP pelo apoio financeiro (Processo $\mathrm{n}^{\circ}$ 04/08635-6) e pela bolsa de mestrado concedida (Processo 06/54619-8).

\section{REFERÊNCIAS}

1. Ghisalberti, E. L.; Bee World 1979, 60, 59.

2. Park, Y. K.; Ikegaki, M.; Alencar, S. M.; Moura, F. F.; Honeybee Sci. 2000, 21,85 .

3. Castro, M. L.; Cury, J. A.; Rosalen, P. L.; Alencar, S. M.; Ikegaki, M.; Duarte, S.; Koo, H.; Quim.Nova 2007, 30, 1512.

4. Soares, S. E.; Rev. Nutr. 2002, 15, 71.

5. Alencar, S. M.; Oldoni, T. L. C.; Castro, M. L.; Cabral, I. S. R.; CostaNeto, C. M.; Cury, J. A.; Rosalen, P. L.; Ikegaki, M.; J. Ethnopharmacol. 2007, 113, 278.

6. Trusheva, B.; Popova, B.; Bankova, V.; Simova, S.; Marcucci, M. C.; Miorin, P. L.; Pasin, R. F.; Evid-Based Complement. Altern. 2006, 3, 249.

7. Li, F.; Awale, S.; Tezuka, Y.; Kadota, S.; Bioorg. Medic. Chem. 2008, 1, 181.

8. Salatino, A.; Teixeira, E. W.; Negri, G.; Message, D.; Evid-Based Complement. Altern. 2005, 2, 33.
9. Teixeira, E. W.; Message, D.; Negri, G.; Salatino, A.; Quim. Nova 2006, $29,245$.

10. Sforcin, J. L.; Fernandes J. R. A.; Lopes, C. A. M.; Bankova, V.; Funari, S. R. C.; J. Ethnopharmacol. 2000, 73, 243.

11. Menezes, H.; Arq. Inst. Biol. 2005, 72, 405.

12. Bankova, V. S.; Castro, S. L.; Marcucci, M. C.; Apidologie 2000, $31,3$.

13. Fernandes, A.; Lopes, M. M. R.; Colombari, V.; Monteiro, A. C. M.; Vieira, E. P.; Cienc. Rural 2006, 36, 294; Basim, E.; Baim, H.; Zcan, M.; J. Food. Eng. 2006, 77, 992; Latif, M. M. M. A.; Windle, H. J.; Homasany, B. S.; Sabra, K.; Braz. J. Pharmacol. 2005, 146,1139.

14. Duarte, S.; Koo, H.; Bowen, W. H.; Hayacibara, M. F.; Cury, J. A.; Ikegaki, M.; Park, Y. K.; Rosalen, P. L.; Biol. Pharm. Bull. 2003, 26, 527.

15. Hayacibara, M.; Koo, H.; Rosalen, P. L.; Duarte, S.; Franco, E. M.; Bowen, W. H.; Ikegaki, M.; Cury, J. A.; J. Ethnopharmacol. 2005, 101, 371.

16. Chen, C. N.; Wu, C. L.; Shy, H. S.; Lin, J. K.; J. Nat. Prod. 2003, 66, 503; Choi, Y. M.; Nohb, D. O.; Choc, S. Y.; Suhd, H. J.; Kimd, K. M.; Kim, J. M.; LWT- Food Sci.Technol. 2006, 39, 756.

17. Awale, S.; Li, F.; Onozuka, H.; Esumi, H.; Tekuza, Y, Kadota, S.; Bioorg. Medic. Chem. 2008, 16, 181.

18. Paulino, N.; Dantas, A. P.; Bankova, V.; Longhi, D. T.; Scremin, A.; Castro, S. L.; Calixto, J. B.; J. Pharmacol. Sci. 2003, 93, 307.

19. Park, J. H.; Lee, J. K.; Kim, H. S.; Chung, S. T.; Eom, J. H.; Kim, K. A.; Chung, S. J.; Paik, S. Y.; Oh, H. Y.; Int. Immunopharmacol. 2004, 4, 429.

20. Sforcin, J. M.; Orsi, R. O.; Bankova, V.; J. Ethnopharmacol. 2005, 98 , 310.

21. Nagai, T.; Inoue, R.; Inoue, H.; Suzuki, N.; Food Chem. 2003, 80, 29; Kumazawa, S.; Hamasaka, T.; Nakayama, T.; Food Chem. 2004, 84, 329.

22. Aso, K.; Kanno, S. I.; Tadano, T.; Satoh, S.; Ishikawa, M.; Biol. Pharm. Bull. 2004, 27, 727.

23. Bankova, V.; J. Ethnopharmacol. 2005, 100, 114.

24. Silva, B. B.; Rosalen, P. L.; Cury, J. A.; Ikegaki, M.; Souza, V. C.; Esteves, A.; Alencar, S. M.; Evid-Based Complement. Altern. 2008, 5, 313.

25. Singleton, V. L.; Orthofer, R.; Lamuela-Raventos, R. M.; Meth. Enzymol. 1999, 299, 152.

26. Brand, W.; Cuvelier, M. E.; Berset, C.; LWT- Food Sci. Technol. 1995 , $28,25$.

27. Ahn, M. R.; Kumazawa, S.; Hamasaka, T.;Bang, K. S.; Nakayama, T.; J. Agric. Food Chem. 2004, 52, 7286.

28. Cabral, I. S. R.; Dissertação de Mestrado, Universidade de São Paulo, Brasil, 2008.

29. Woisky, R. G.; Salatino, A.; J. Apicultural Res. 1998, 37, 99.

30. Halliwell, B.; Gutteridge, J. M. C.; Free Radicals in Biology and Medicine, $4^{\text {th }}$ ed., Oxford: UK, 2007.

31. Wang, B. J.; Lien, Y. H.; Yu, Z. R.; Food Chem. 2004, 86, 237.

32. Moraes-de-Souza, R. A.; Oldoni, T. L. C.; Regitano-d'Arce, M.; Alencar, S. M.; Cienc. Tecnol. Aliment. 2008, 6, 41.

33. Vasco, C.; Ruales, J.; Kamal-Eldin, A.; Food Chem. 2008, 111, 816; Lim, Y. Y.; Lim, T. T.; Tee, J. J.; Food Chem. 2007, 103, 1003.

34. Han, J.; Weng, X.; Bi, K.; Food Chem. 2008, 106, 2; Atmani, D.; Chaher, N.; Berboucha, M.; Ayouni, K.; Lounis, H.; Boudaoud, H.; Debbache, N.; Atmani, D.; Food Chem. 2009, 112, 303.

35. Arnao, M. B.; Trends Food Sci. Technol. 2000, 11, 419; Blois, M. S.; Nature 1958, 181, 1199.

36. Marco, G. J.; J. Am. Oil Chem. Soc. 1968, 45, 594.

37. Moure, A.; Cruz, J. M.; Franco, D.; Dominguez, J. M.; Sineiro, J.; Dominguez, H.; Nunez, M. J.; Parajo, J. C.; Food Chem. 2001, 72, 145.

38. Koleva, T. A.; van Beek, T. A.; Linssen, J. P. H.; de Groot, A.; Evstatieva, L. N.; Phytochem. Anal. 2002, 13, 8.

39. Oldoni, T. L. C.; Dissertação de Mestrado, Universidade de São Paulo, Brasil, 2007.

40. Rice-Evans, C. A.; Nicholas, J. M.; Paganga, G.; Free Radical Biol. Med. 1996, 20, 933. 